\title{
THE IMPORTANCE OF INTERDISCIPLINARY RELATIONS OF PHYSICS AND STATICS
}

The article will discuss the importance of respecting and applying the didactic principle of interdisciplinary relations in Physics and Statics taught at the University of Security Management in Kosice. The subjects Statics and Physics, which are based on natural principles, allow to get the necessary analytical and logical thinking for understanding other technical and science subjects. Application of the principle of interdisciplinary relations helps to increase efficiency and quality of the teaching process, motivates and activates students. The article describes the possibilities of using physical knowledge in the subject Statics.

Keywords: Interdisciplinary relations, teaching process, physics, statics.

\section{Introduction}

The quality and content of higher education is currently a frequently discussed issue in society. For students, university is not only a source of information and knowledge, but through university teachers it provides them with skills and treatment of theoretical methods that help students classify, process and adequately apply in an effective manner the acquired information in practice.

The objectives and tasks of the teaching process help create optimal conditions for the conscious and positive activity of well-educated and skilled security managers of different specializations [1]. The current dynamic changes in our society will be substantially reflected in the structure and functioning of the labor market. The various professions are changing as fast as the demands of employers, which in turn, necessitates a rapid response in education and training systems [2]. The aim of education is to prepare a group of experts for the management of security institutions of different sizes and varying degrees of complexity. It is necessary to develop and clarify its own terminology of the relevant terms, used in the preparation of security experts - in education of security management specialists [3].

Nowadays, higher education goes through a number of changes - the changes in the curriculum, forms of education and methods of knowledge evaluation. Changing the content of the curriculum is not an exception - the reduction of unnecessary, non-functional information and replacing it with the content and knowledge necessary for practice, which can be used and applied by students in practice. This modification is also possible due to the systematic application of the didactic principle of respecting interdisciplinary relations.

A didactic principle of respecting interdisciplinary relations in teaching requires that any new knowledge be created by building on the knowledge of other sciences. By application of interdisciplinary relations and links the knowledge isolation is overcome, which leads to a reduced amount of unnecessary, non-functional information, substitution of its content by the knowledge necessary for life.

In order to meet the main objective of university study, namely the real usability of the acquired knowledge in practice, there should be a change in course content. Durability of the acquired knowledge is affected by various factors and, in certain circumstances it may be extended. Only the acquired information, which has previously been sufficiently understood by the student and processed in his consciousness, can become student's permanent property.

In an effort to educate as many graduates as possible to approach the ideal graduate profile it is necessary for the learning process to be optimal, rational and efficient. The teaching process has its own set of goals that must be achieved in due time. This is associated with the energy expended by both the teacher and the student, from which then arise adequate results of teaching activities in relation to time and energy. To make the learning process effective and meet its objectives, the teacher must use teaching methods, material resources, apply the principles of teaching, create organizational forms and, finally, apply

\footnotetext{
* Martina Vackova, Maria Kancirova, Lucia Kovacova

Institute of Humanitarian and Technological Science, University of Security Management in Kosice, Slovakia

E-mail: martina.vackova@vsbm.sk
} 
interdisciplinary relations, as the acquired knowledge is without connections and contexts fragmented.

The need to address this issue from a didactic point of view, we focus on two study subjects, Physics and Statics, which are included in the study programme Management of Security Systems at the University of Security Management in Kosice (USM). Physics and Statics arise from natural laws, both enabling to acquire necessary analytical and logical thinking for understanding other Technical and Natural Science Subjects. The role of these subjects in the field of study Protection of Persons and Property and the present study programme is to enable students to acquire basic analytical capability necessary for addressing a number of technical problems and acquire knowledge necessary for passing other subjects, particularly Elasticity and Strength. These subjects create a solid and logical basis for, particularly, technical studies. The fact that the graduate of the study programme Management of Security Systems, the field of study Protection of Persons and Property also acquires knowledge of Technical Sciences is appropriate.

\section{Interdisciplinary relations}

Interdisciplinary relations can be understood as the intersection of a particular topic and the curriculum content of different subjects or methods of work and the use of these links in knowledge systematization. We define them as links between elements of didactic systems of different subjects. They are based on the content matches of the curriculum content of individual subjects (content bonds), common methods and forms of work (methodological bonds) and the temporal link of the curriculum of individual subjects (time binding).

The aim of interdisciplinary relations is the projection of knowledge of several subjects into a comprehensive picture of reality. An important factor here is the coordination of teaching in related subjects and timing of the topics covered [4].

The application of interdisciplinary relations in teaching provides the student with a comprehensive view of things. Its advantage is the change of the student's view of the possibility of applying the acquired knowledge, which undoubtedly leads to increasing his motivation. On the other hand, the application of interdisciplinary relations requires intensive preparation by the teacher. The educator must find suitable topics and prepare materials for them. If one decides for interdisciplinary teaching, he must cooperate with the other teacher and synchronize the inclusion of topics in the curricula with him. From the point of view of the teacher time saving in teaching is an advantage, as the teacher may refer to the knowledge of the other subject, the duplication is removed [5].

The implementation of interdisciplinary relations should already start in curriculum and teaching plans and the further analysis of the curriculum in each of the subjects should be reflected in the textbooks and other teaching aids necessary for educators and students, as well as in the work in this field.

Interdisciplinary relations as a didactic means allow a better systematization of knowledge, as they develop the ability to synthesize and transfer knowledge from one subject to another. Their purposeful application allows you to remove the often artificial boundaries between subjects [6].

\section{The application of the didactic principle of interdisciplinary relations of Physics and Statics}

The reason for the application of the didactic principle of interdisciplinary relations in the teaching of Statics and Physics at the University of Security Management was that university teachers began to realize that students had a distance of these subjects, considering them difficult and hard to understand, useless. For the teachers the aim was to arouse the students interest in these subjects by applying interdisciplinary relations, and thus motivate them more effectively. At the USM the subject of Physics is taught in the first year of the summer semester, in the scope of 2 lectures, 1 practice lesson. Statics is taught in the 2nd year of the winter semester, 2 lectures and 2 practice lessons.

The main objective of teaching Physics at the USM in Kosice is to provide students with the basic knowledge and demonstrate the possibilities of application of the acquired knowledge and expertise in downstream subjects, specialized and profiling. From the point of view of the application of physical knowledge Physics and Statics have much in common.

The use of Physics in the subjects of Mechanics has its roots in the distant past and the development of Mechanics was also influenced by the solution of physical problems. Gradually Mechanics separated from Physics as an independent scientific discipline exploring mechanical movement of material (tangible) objects. Mechanics of solid bodies can be divided into [7]:

1. Mechanics of solid bodies and mechanical systems - where we can include the subject of Statics.

2. The mechanics of pliable bodies - where we include Elasticity and Strength.

The content of the subject of Physics is focused on the deepening, consolidating, broadening of the knowledge and skills acquired in the previous stage of education. An important goal of teaching Physics at the USM in Kosice is to provide students with the basic knowledge of Physics and, in particular, to demonstrate the possibilities of the application of the physical apparatus in the subjects in the field of Mechanics and in practice. The emphasis is laid on knowledge systematization, integration and generalization.

The scope of the issues is aimed at familiarization with the conceptual apparatus, basic laws and ideas of the growing importance of Physics for the development of Natural and Technical Sciences and the development of human society. In 
Physics students acquire basic knowledge of vector quantities, vector calculus and laws needed for the follow-up study in subjects such as Statics, Elasticity and Strength, etc.

The subject of Statics enables students to acquire basic analytical capability to address many technical problems. It provides knowledge of the theory of force systems, static solution to the systems of bodies including the bar systems without and with passive resistance. At the same time it is the basis for understanding another subject of this field: Elasticity and Strength. Statics' scope is chosen to suit the requirements to be met by graduates in this field of study. It is focused on selected parts of Statics only, which are beneficial for students to cope with other subjects, and not to bring opacity to this subject or overburden students with lots of knowledge and tasks. Statics teaches you to understand, logically explain and justify a lot of everyday phenomena, commonly encountered in your area. Its application in various activities will enable doing things more safely and more efficiently. Therefore, it is necessary to acquire the basic knowledge of technical subjects as well, to which Statics undoubtedly belongs [8].

The content of the course syllabus of Statics [9]:

- Basic concepts and terms of mechanics. Basic axioms of statics and the consequences resulting from them. Force and Force systems. The linear force system. The central force system (planar, spatial). Point links in the plane.

- Sliding and rotating effect of a force. Moment of a force about a point. Possible effects of force systems. Shape and static determination of structure. General and parallel force system (planar, spatial).

- Moment of a force about a skew axis. The resulting effect of a force and moment in space.

- Center of tied parallel force system. Center of geometric shapes. Center of gravity of material objects (bodies). Linear load.

- Planar system of bodies and bar systems.

The content of the course syllabus of Physics [10]:

- Subject, methods and division of Physics. Physical quantities. Units of physical quantities. The International System of Units (SI).

- The basic relations of vector algebra.

- Kinematics of a material point, basic quantities characterizing the motion, motion classification. Dynamics of a material point. Newton's laws of dynamics, momentum, impulse of force, moment of force and angular momentum, energy, work, power, kinetic and potential energy, law of conservation of mechanical energy.

- Newton's universal law of gravity. Intensity and potential in a gravitational field. Movement of bodies in a gravitational field.
Introduction to molecular physics and thermodynamics, kinetic theory of matter, total and internal energy of the system, temperature, heat, heat capacity, specific heat capacity and molar heat capacity, calorimetric equation, ideal gas, root mean square (rms) velocity, mean kinetic energy of the gas molecule, equation of state, working gas volume, laws of thermodynamics and actions.

Mechanical oscillations and waves - basic concepts and terms. Undamped harmonics. Energy of harmonic oscillator. Muffled (damped) oscillations. Forced oscillations and resonance. Harmonic analysis. Formation of waves and basic concepts. Wave equation. The equation of a plane wave.

- Electromagnetic oscillations. LC oscillation circuit. RLC oscillation circuit and resonance. Formation and properties of harmonic alternating current. Effective values of voltage and current. Work and power of alternating current. Electromagnetic waves and their propagation.

- Electromagnetic theory of light, wave properties of light.

In Statics, since the first week of teaching, it is obvious that students need to have mastered the curriculum of vector algebra, to be able to perform vector operations: addition and subtraction of vectors (in analytical and graphical form), scalar and vector product. Students acquire this knowledge in Physics. Therefore, even in the beginning of teaching Physics it is very important to apply the interdisciplinary relations and motivate students in learning vectors and operations with them.

A student who wants to study Statics successfully must have mastered the physical apparatus that is used. And vice versa, a good motivation for students in the study of Physics may be the inclusion of the applications of Physics in teaching Statics. As regards higher education, the focus is mainly on the feasibility and usefulness of the acquired knowledge in practice.

Educators in Statics require that students must have the ability to apply the knowledge of Physics, methods in scientific disciplines and to solve problems of engineering practice. They are required to have skills and abilities necessary for the use

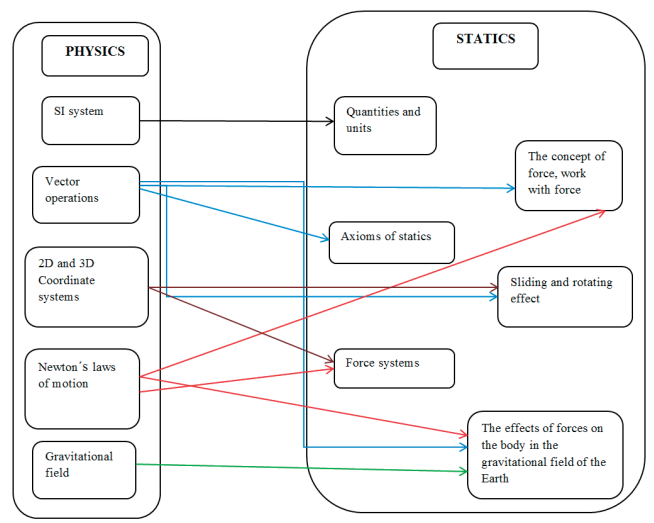

Fig. 1 The application of the didactic principle of interdisciplinary relations between Physics and Statics 
of a physical apparatus allowing them to gradually master the solution of technical problems. In view of these requirements, the teaching of Physics at the University of Security Management in Kosice has begun to be focused more on the application of the knowledge of Physics, practices and methods to problems that occur in specialized subjects such as Statics. All this, however, cannot be achieved without the cooperation of teachers of Physics with the teachers, who cover the subject of Statics.

Based on the close relationship between Physics and Statics the didactic principle of interdisciplinary relations has started to be applied at the University of Security Management. In preparing the teaching plans of the subjects the teachers closely cooperate. The application of interdisciplinary relations of these subjects is shown below (Fig. 1).

In Fig. 1 we can see how closely the two subjects are linked. The knowledge acquired by students in Physics, are applicable in the subject of Statics. Therefore, we would like to say that the application of the didactic principle of interdisciplinary relations between these subjects is necessary and important, and not least, nowadays, it is the best way to educate as many graduates as possible the way to approximate to the ideal profile of graduate who will use in practice the knowledge acquired at the university.

\section{Conclusion}

Knowledge is part of the flow of information acquired by students every day, further processed, and possessed by them.
The role of university teachers is to provide students with the knowledge that can be used in practice after graduation. Therefore, it is important to respect the didactic principle of interdisciplinary relations. Observing and respecting this principle may result in changing the view of the possibility of applying the acquired knowledge in other areas, which will undoubtedly increase student motivation. An important assumption of durability is that the student learns in depth, understanding the meaning and logic of the issue.

The aim of the paper was to highlight the importance of the didactic principle of respecting the interdisciplinary relations between the subjects Statics and Physics taught at the University of Security Management in Kosice. Combining teaching methods we can stimulate students" interest in studying Physics and Statics. We create the appropriate conditions for the development of interdisciplinary relations and for improving the quality of higher education at the University of Security Management in Kosice.

A suitable combination of the traditional and modern teaching methods can stimulate students' interest in learning; create conditions for the development of interdisciplinary relations and for improving the quality of higher education. The didactic principle of respecting interdisciplinary relations should be applied by educators of all types of schools, those wishing to motivate their pupils and students properly and purposefully for their further education. Because only properly and purposefully motivated student has the desire to learn, expand his knowledge and is able to apply the acquired knowledge in practice.

\section{References}

[1] KOVACOVA, L., KLIMO, V.: Fundamentals of Security Education in the Process of Globalization, Odes 'kyi Politechnichnyi Universytet Pratsi, No. 2 (41), 2013, Odesa, pp. 217-222, ISSN 2076-2429.

[2] KAVAN, S.: Training in Water Management with a Focus on Crisis Management (in Czech), Proc. of conference Increasing the efficiency of the educational system in crisis management in the field of internal security. Policejni akademie CR v Praze, 2014. ISBN 978-80-7251-425-0.

[3] LOSONCZI, P., MESAROS, M.: Asymmetry of Understanding Access to the Information Protection (in Slovak). Kosicka bezpecnostna revue, vol. 2, No. 1, University of Security Management in Kosice, 2012, pp. 28-30, ISSN 1338-4880.

[4] SLAVIK, M. et al.: University pedagogy. For Vocational Training - ${ }^{\text {st }}$ ed. (in Czech). Praha: Grada Publlishing, 2012, 256 p. ISBN 978-80-247-4054-6.

[5] PODLAHOVA, L. et al.: Didactics for University Teachers - $1^{\text {st }}$ ed. (in Czech), Praha : Grada Publlishing, 2012, 160 p., ISBN 978 80-247-4217-5.

[6] VAGASKA, A.: Some Aspects Interdisciplinary Relations of Mathematics and Mechanics (in Slovak). Proc. of conference Mathematics in school today and tomorrow. Katolicka univerzita : Ruzomberok, pp. 68-71, 2003.

[7] BUSOVA, B., CABAN, S., ZIARAN, S.: Mechanics I. - Statics (in Slovak), Bratislava : Alfa, 1992, 272 p. ISBN 80-05-01053-2.

[8] PAVLENKO, S, HALKO, J., LITECKA, J.: Training of Teachers in the Development of Spatial Imagination of Pupils of Elementary and Secondary Schools as a Foundation of Technical Thinking - study material - $1^{\text {st }}$ ed. (in Slovak), Presov : FVT TU, 2011, 100 p., ISBN 978-80-553-0842-5.

[9] KLIMO, V., CABAN, S., MESAROSOVA, L.: Statics (in Slovak), University of Security Management in Kosice, 2008,137 p., ISBN 978-80-89282-13-5.

[10] KOMOVA, E., SEMRAD, K.: Physics for Safety Management (in Slovak), University of Security Management in Kosice, 2007, 129 p., ISBN 978-80-89282-07-4. 